\title{
Temperature Distribution Pattern of Brassica chinensis during Vacuum Cooling
}

\author{
Xiao-yan Song, Bao-lin Liu, and Ganesh K. Jaganathan \\ Institute of Cryobiology and Food Freezing, University of Shanghai for Science and Technology, 516 Jungong Road, \\ Shanghai 200093, China \\ Correspondence should be addressed to Bao-lin Liu; blliuk@163.com
}

Received 30 October 2015; Revised 29 December 2015; Accepted 7 February 2016

Academic Editor: Xuetong Fan

Copyright (C) 2016 Xiao-yan Song et al. This is an open access article distributed under the Creative Commons Attribution License, which permits unrestricted use, distribution, and reproduction in any medium, provided the original work is properly cited.

\begin{abstract}
The temperature distribution of leafy vegetables is often less uniform than that of other vegetables during the vacuum cooling process, a factor that can cause undesired effects such as frostbite. Brassica chinensis, a type of classical leafy vegetable, was used as a model in this paper to optimize vacuum cooling technology for the whole and fresh-cut leafy vegetables. We found that noticeable temperature differences between the leaf and the petiole occurred, which resulted from their structural difference. Temperature variations of different parts of the leaf were also observed, indicating that cooling rate of leaf margin was quicker than the other parts. Our experiments show that using a moderate volumetric displacement of the chamber $\left(0.033 \mathrm{~s}^{-1}\right)$ is beneficial for obtaining a relative uniform temperature distribution of the leaf part.
\end{abstract}

\section{Introduction}

Maintaining high quality of fresh-cut vegetables is a major problem in food processing industry because cutting and shredding often deteriorate the physiology of fresh-cut vegetables more rapidly than the whole vegetables [1]. Such physiological degeneration is an apparent problem for some extremely sensitive vegetables such as harvested broccoli, as it can accelerate the browning process [2]. Of all the related factors contributing to deterioration, temperature is critical, because respiration rate increases with increasing product temperature $[3,4]$. So, the time to cool the fresh-cut vegetable to optimum storage temperature should be minimal. Further, because the cut section of the fresh vegetables can undergo oxidation and is susceptible to microorganism growth, a clean and rapid cooling technology such as vacuum cooling is suitable for the fresh-cut vegetables [5, 6].

Vacuum cooling is a very effective process for cooling foods with a high water content and large porosity, as the water within or from the outside of the food can absorb heat from food via evaporation [7-9]. Consequently, it can enhance the microbial safety of raw products significantly during the cooling process and storage period [10]. Despite using vacuum cooling for more than sixty years to store leafy vegetables in commercial operations, this technique is still not widely used due to its limitations such as more uniform temperature distribution, lower water loss rate, and lower energy conservation [11-14]. Amongst these three aspects, temperature distribution requires particular attention especially for the leafy vegetables, because marked temperature differences can often be observed between the leaf and the petiole during the vacuum cooling. However, there is still a lack of understanding on this temperature difference. This gap in knowledge has not only hampered designing new equipment and improving the technology, but also is a bottleneck for deriving the mathematical model for the leafy vegetables being vacuum cooled. Thus, the main aim of this paper is to study the temperature changing pattern in the whole and fresh-cut Brassica chinensis by monitoring its surface and cut section temperature distributions during the vacuum cooling process via an infrared thermal imaging equipment (see Section 2 for details) $[13,15]$.

Given numerous obvious advantages of vacuum cooling technology, a plethora of studies has spawned to optimize the various components of the instrument in order to reach higher quality of product at the end of storage. A key focus of 


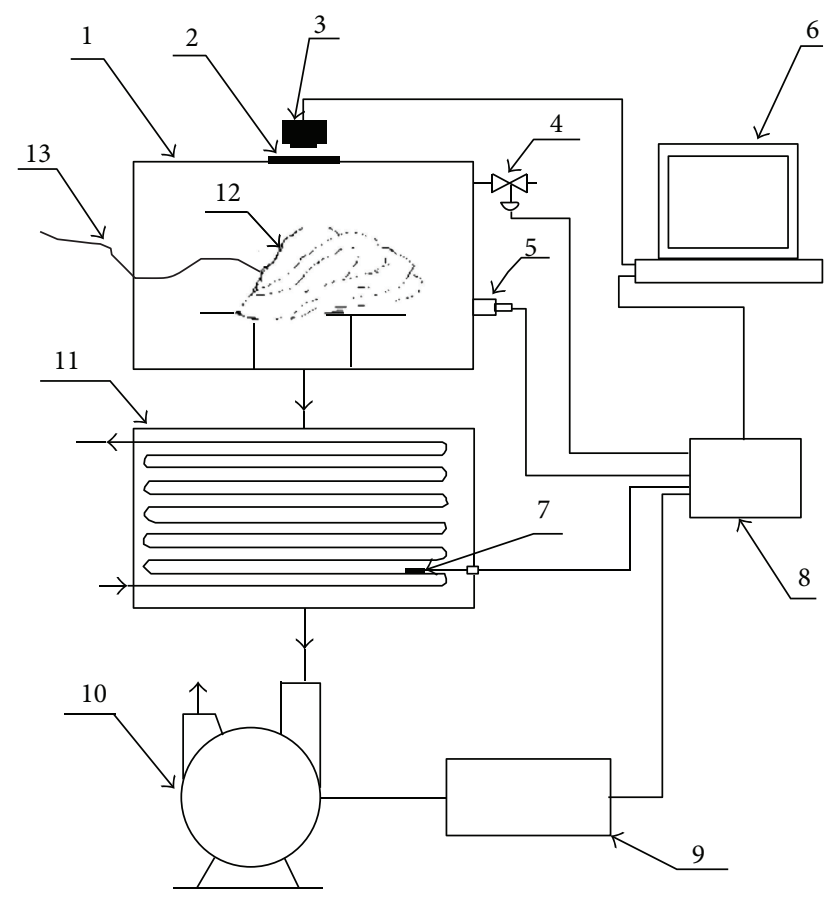

FIGURE 1: Schematic diagram of the vacuum cooler: (1) vacuum chamber; (2) infrared window fixed at the top of vacuum chamber; (3) online infrared thermal imager; (4) electromagnetic bleeding valve; (5) pressure sensor; (6) computer; (7) temperature sensor; (8) programmable logic controller; (9) frequency converter; (10) vacuum pump; (11) cold trap; (12) sample; and (13) standard temperature sensor used to real-timely calibrate the infrared thermal imaging equipment.

many of these studies is the effect of pressure reduction rate on the physical and chemical quality characteristics as well as the ultrastructure of leafy vegetable $[10,12,16]$. For instance, $\mathrm{He}$ et al. found that the moderate pressure reduction rate achieved the maximum values of tissue firmness, ascorbic acid and catalase, and best quality and shelf-life of iceberg lettuce [16]. However, few studies have been carried out to reveal the relation between real-time temperature distribution of leafy vegetable surface and volumetric displacement of pump. Consequently, vacuum cooling with different volumetric displacements is worthy of further study.

\section{Materials and Methods}

2.1. Sample Preparation. Freshly harvested Brassica chinensis (Cruciferae) with water contents of $92 \% \pm 2.5 \%$ and $95 \% \pm$ $2.7 \%$ for petiole and leafy part, respectively, grown in Nanhui farm, Shanghai, China, was carefully picked and transported to our lab, where the experiments were conducted. The leaves were stored in $18 \pm 0.5^{\circ} \mathrm{C}$ and $95 \pm 1 \%$ relative humidity (highly accurate relative humidity/temperature probe, precision of $\pm 0.1 \%$ and $\pm 0.2^{\circ} \mathrm{C}$, TESTO $435-4$, Germany) box before the experiments were conducted.

2.2. Vacuum Cooling and Temperature Measurement. Figure 1 depicts the experimental setup consisting of a vacuum chamber, an infrared window, an online infrared thermal imager, an electromagnetic bleeding valve, a pressure sensor, a vacuum pump, a frequency converter, a programmable logic controller, a cold trap, two temperature sensors, and a computer.

The vacuum chamber, where the samples were processed, was made from organic glass (polymethyl methacrylate) with a thickness of $0.01 \mathrm{~m}$ and a volume of $0.045 \mathrm{~m}^{3}$. The sensitive infrared thermal imaging system (Testo, 885-2, Germany) put in the vacuum chamber and the infrared window were used together to measure the real-time temperature of the Brassica chinensis surface. The vacuum pump (Leybold, D8C, Germany) and the frequency converter (SINAMICS, V10, Germany) were combined to reduce the total pressure which was detected by the pressure sensor (Testo, 4354 , Germany) and to stabilize the pressure at $600 \pm 50 \mathrm{~Pa}$ with the help of the electromagnetic bleeding valve until the vacuum was released. Under the control of the programmable logic controller (SINAMICS, S7-224, Germany), the frequency converter supplies the vacuum pump various power according to the set rotational frequency values to get different volumetric displacements. The cold trap was used to gather the water vapor coming from the vacuum chamber. Both the control task and data collection were performed by the programmable logic controller with the help of a programming software (STEP 7-MicroWin V4.0.8.06).

This experimental setup runs as follows: (a) when the cold trap was cooled to $-6^{\circ} \mathrm{C}$ measured by the temperature sensor, both the vacuum pump and frequency convertor were switched on and the pressure of vacuum chamber was reduced to $600 \mathrm{~Pa}$ continuously in a constant volumetric displacement. The cold trap was maintained between -12 and $-15^{\circ} \mathrm{C}$; (b) once the pressure of vacuum chamber reached $600 \mathrm{~Pa}$, the bleeding valve was autoadjusted to match the volumetric displacement of vacuum pump so that the final pressure of vacuum chamber was stabilized at $600 \mathrm{~Pa}$; (c) the infrared thermal imaging system worked during the whole vacuum cooling process to record the development of the temperature distribution of $B$. chinensis surface. Because the emissivity of leaf surface (0.9-0.98), IR transmittance of the infrared window material (0.7-0.8), machine temperature $\left(20^{\circ} \mathrm{C}-25^{\circ} \mathrm{C}\right)$, measurement distance $(0.25 \mathrm{~m})$, and related humidity (70\%-95\%) in vacuum chamber can make a big impact on the accuracy of the temperature obtained using an infrared thermal imager, a standard thermocouple (precision of $\pm 0.5^{\circ} \mathrm{C}$, Omega-5TC-KK-T-20-72, USA) adhering to the reverse surface of leaf was used to detect the $\mathrm{T} 5$ (temperature of point 5) (Figure 2). Each thermal image was calibrated by adjusting the relative parameters according to $\mathrm{T} 5$ obtained by the thermocouple. Then, T1-T8 (temperatures of points 1 to 8 ) were extracted every 5 seconds from the calibrated thermal images. T9 was the average value of T1-T6. T10 was the average value of $\mathrm{T} 7$ and $\mathrm{T} 8$.

2.3. Statistical Analysis. SPSS (version 18.0) was used to evaluate the effect of different volumetric displacements of pump $\left(0.022 \mathrm{~s}^{-1}, 0.033 \mathrm{~s}^{-1}\right.$, and $\left.0.044 \mathrm{~s}^{-1}\right)$ on the temperature uniformity of the leaf part during the vacuum cooling process 


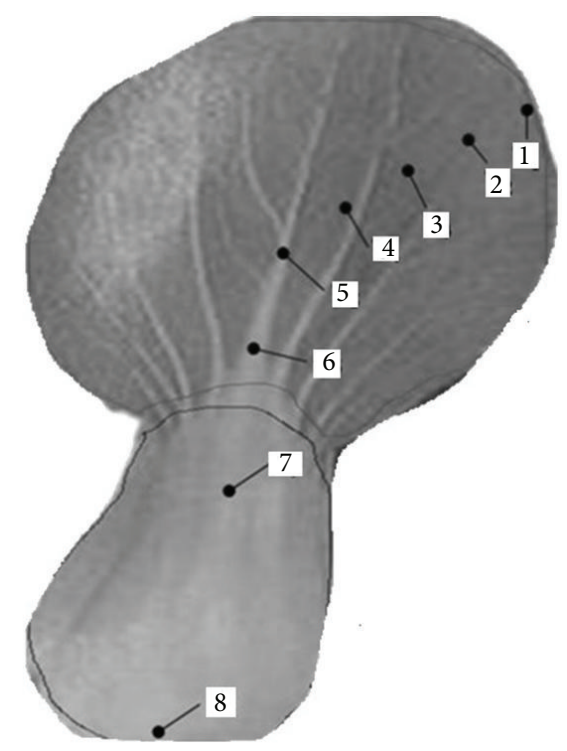

Figure 2: Points to evaluate the temperature uniformity of the sample.

in analysis of variance (one-way ANOVA) at $p<0.05(N=$ $6)$.

\section{Results and Discussion}

3.1. Overall Temperature Distribution of the Whole Brassica chinensis during Vacuum Cooling. Our results confirmed that different parts of Brassica chinensis had different temperatures during vacuum cooling process. This difference is more apparent during the first $1260 \mathrm{~s}$ of cooling, where mean temperatures of petiole and leaf were $17^{\circ} \mathrm{C}$ and $10^{\circ} \mathrm{C}$, respectively (Figures 3(a)-3(c)). The slower reduction in temperature around petiole region can be attributed to the thicker tissues with higher water content [17]. However, after cooling the samples for another $420 \mathrm{~s}$, the mean temperature of the petiole reached very close to that of the leaf (Figure $3(d)$ ), indicating thicker structures of the petiole require more time for reducing temperature. When the vacuum was released, the mean temperature of the leaf rose to $23^{\circ} \mathrm{C}$ rapidly (Figure 3(e)), because the chamber temperature was always kept at a constant value [18]. However, the temperature of the petiole did not change markedly compared with the leafy part after vacuum was released. It was because the petiole is much thicker than the leafy part and has a higher water content; thus its heat capacity is greater than that of the leaf. In addition, there was no effective way for water to evaporate from the outside surface of the petiole; the outside skin of the petiole is composed of a wax coat, which conducts heat poorly.

\subsection{Overall Temperature Distribution of the Fresh-Cut Brassica} chinensis during Vacuum Cooling. The temperature distribution in the fresh-cut vegetables mirrored the results obtained for full vegetables. Thus, the petiole cooled more quickly than the leafy part (Figures 4(a)-4(d) compared with Figure 3).
In particular, the portion close to the cut edge cooled much faster than other parts during the cooling process. With the temperature drop of this part, the mean temperature of the petiole was lower than that of the leafy part in the same fresh-cut vegetable at the end of the vacuum cooling process (Figure 5).

3.3. Temperature Changes at Different Points of the Leaf during the Vacuum Cooling Process. Figure 6 shows that the temperature of different points on the leaf decreased with the drop of total pressure in the vacuum chamber. This occurred in the following manner: firstly, temperatures of all the points were kept unchanged until the vacuum chamber was pumped to the "flash point" when the free water inside the leaf evaporated suddenly; then, after reaching the "flash point," the temperature of each point dropped quickly. But the temperature just dropped down to $11.3^{\circ} \mathrm{C}$, which may have been because (1) the sample was heated in main way of infrared radiation by the vacuum chamber which was hotter than the samples or (2) the sample was heated by the wet air in the vacuum chamber [18].

During the vacuum cooling process, the structural factors such as the size and porosity of the sample have a critical effect on the temperature drop rates of different parts of the sample [19]. Figure 6 showed that the final temperature of leaf from points 1 to 5 was reduced. This phenomenon may be related to the numerous stomas, because the free water inside the leaf is primarily evaporated through stoma on the lower epidermis transpiration process [20]. However, the stoma could close if the water inside the leaf is not sufficient. This implies that the ability to obtain moisture from the petiole should be considered as a key factor affecting the final temperature of Brassica chinensis during vacuum cooling, especially for the leaf part. Because the mesophyll cells absorbed the remainder free water tightly and the moisture inside leaf was transported mainly by veins at the end of vacuum cooling process, the ability to obtain moisture from the petiole decreased with the increasing distance from the petiole. So, if the measured points were affected by the same degree of thermal radiation coming from the vessel wall and affected by the same thermal convection coming from the wet air, the final temperature would be expected to decrease from points 1 to 5 .

\subsection{Effect of Volumetric Displacement on the Temperature Dis-} tribution of Leaf during the Vacuum Cooling Process. In this paper, the standard deviation of T1-T6 under same cooling condition was used to evaluate the uniformity of temperature distribution of Brassica chinensis surface. In general, a smaller standard deviation means a better uniformity. Figure 7 shows that uniformity obtained from the experiments using the volumetric displacement of $0.044 \mathrm{~s}^{-1}$ was lower than that of both $0.022 \mathrm{~s}^{-1}$ and $0.033 \mathrm{~s}^{-1}(p<0.05)$ cooling. This result agrees with the previous study, which claimed that a smaller pressure drop rate was recommend for natural casing sausages during the immersion vacuum cooling [21]. However, the pressure drop rate should be adjusted according to the food category. For instance, Feng and Sun [21] also found that the recommended pressure reduction rate was $30 \mathrm{mbar} / \mathrm{min}$ for artificial casing sausages compared with 20 


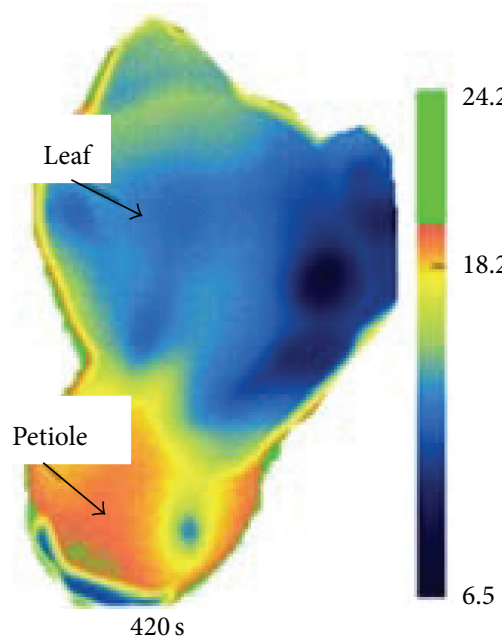

(a)

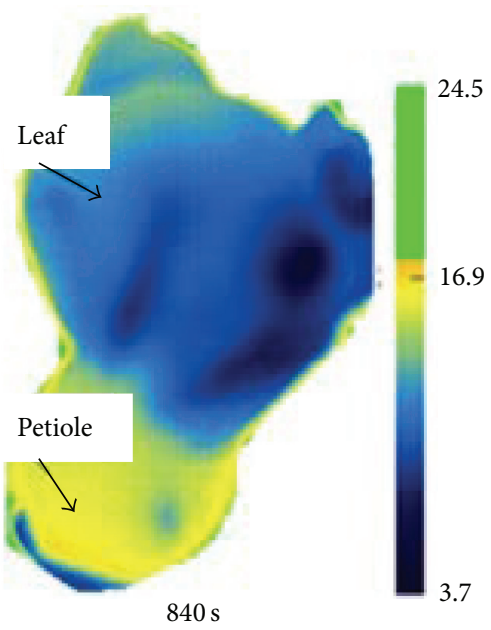

(b)

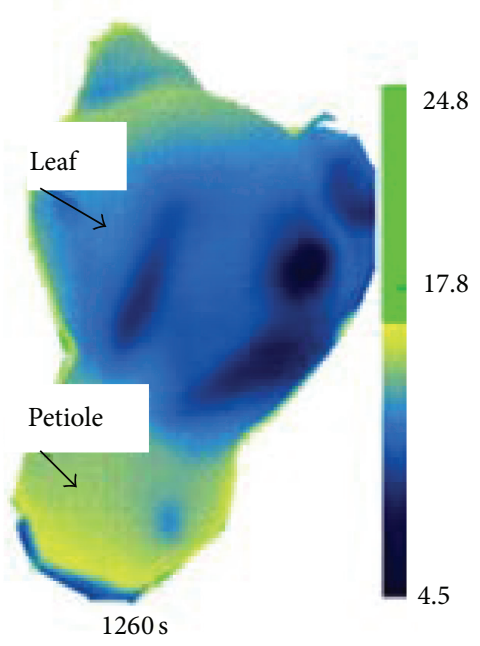

(c)

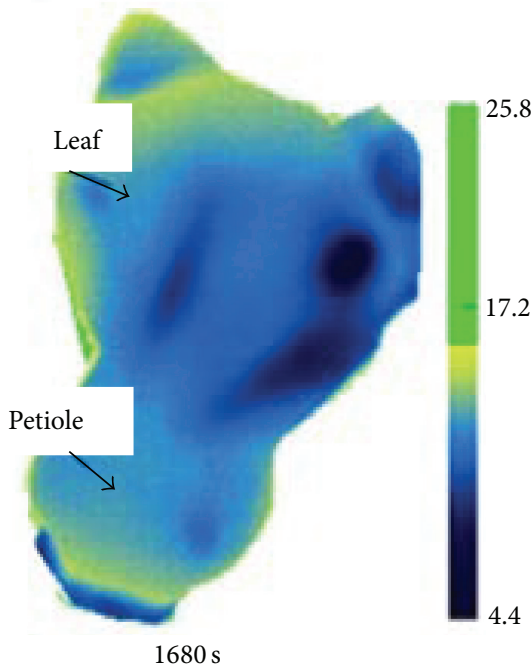

(d)

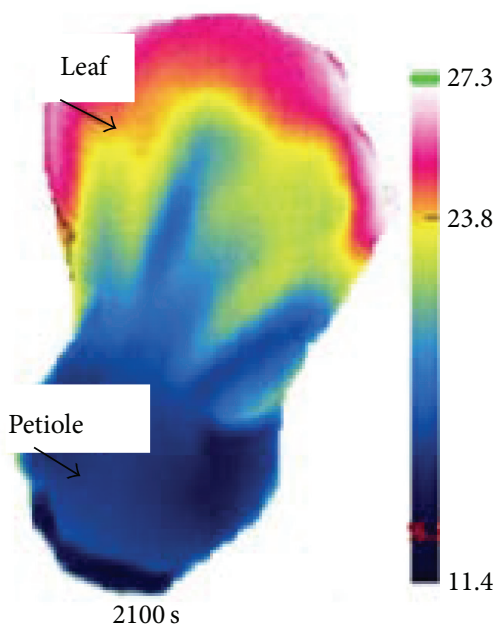

(e)

FIGURE 3: Thermal infrared images of intact sample at different stage during vacuum cooling.

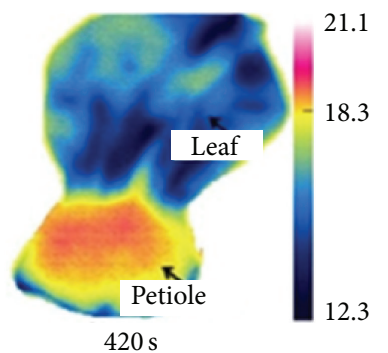

(a)

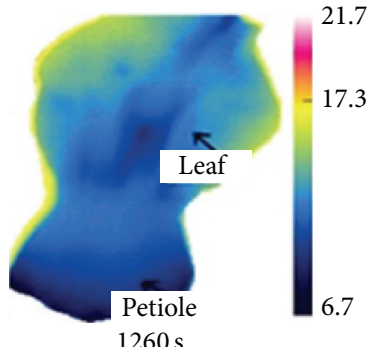

(b)

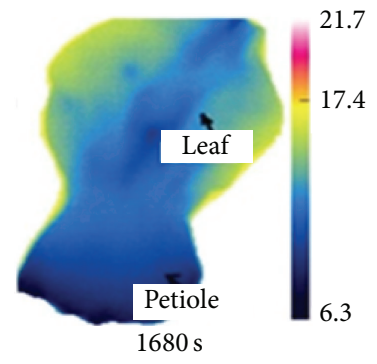

(c)

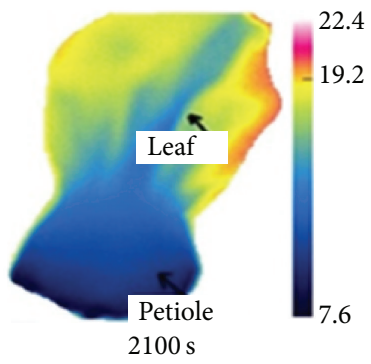

(d)

FIgURE 4: Thermal infrared images of fresh-cut sample at different stage during vacuum.

and $40 \mathrm{mbar} / \mathrm{min}$. Song and Liu found that only properly varying the volumetric displacement can result in uniform temperature distribution across the ham section during the vacuum cooling process [14]. In this study, we also found that employing the volumetric displacement of $0.033 \mathrm{~s}^{-1}$ caused a better uniformity than $0.022 \mathrm{~s}^{-1}(p<0.05)$. So, volumetric displacement must be moderate for Brassica chinensis during the vacuum cooling process. 


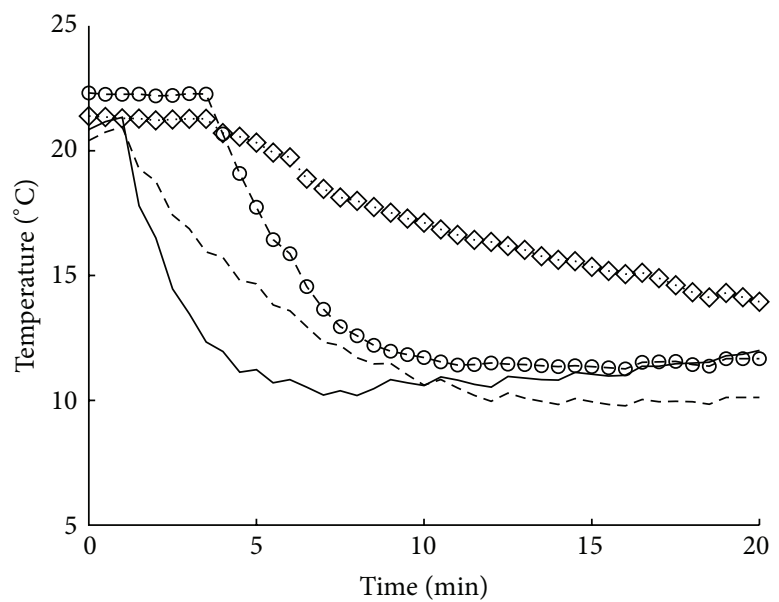

— T9 (cut vegetables) leaf $\quad$ - $\odot-$ T9 (complete vegetables) leaf - - - T10 (cut vegetables) petiole .... T10 (complete vegetables) petiole

Figure 5: Temperature changes in leaf and petiole of whole and fresh-cut samples during vacuum cooling.

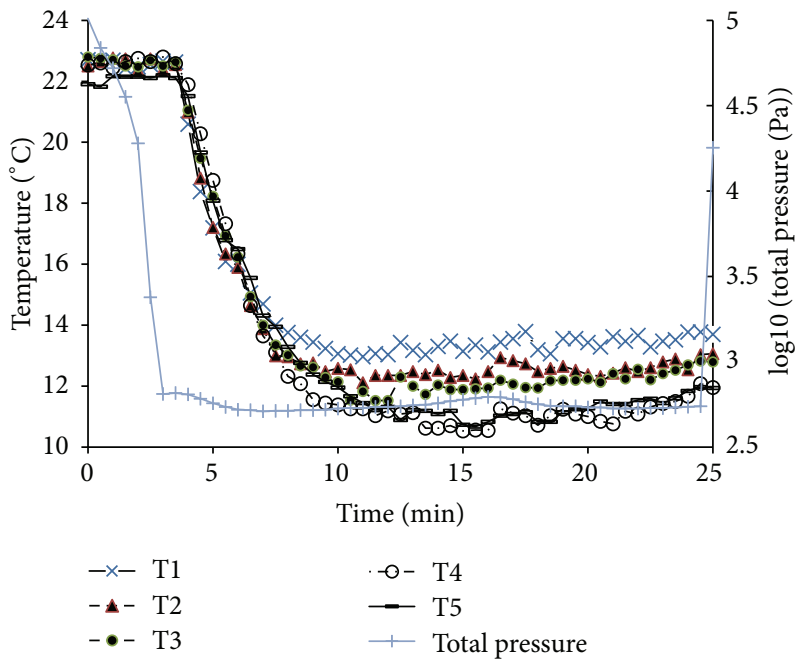

FIGURE 6: Temperature developments of different points at leaf part.

\section{Conclusions}

With the help of infrared thermal imaging technology, the surface temperature of Brassica chinensis was detected during the vacuum cooling process. The results show that the broad and thin leaf cooled more easily than the thick petiole if the vegetable was intact, especially if the petiole had not been damaged. If a part of the petiole was cut off, the temperature of the part nearest to the cut decreased more quickly than the leaf. In addition, the cooling rate of the leaf was reduced during the vacuum cooling process because the free water used for refrigeration was drawn away by the damaged petiole.

Temperature differences were also observed among different parts of the leaf part. The leaf margin cooled most quickly at the beginning of the vacuum cooling process. However, this trend disappeared after a short time, as the

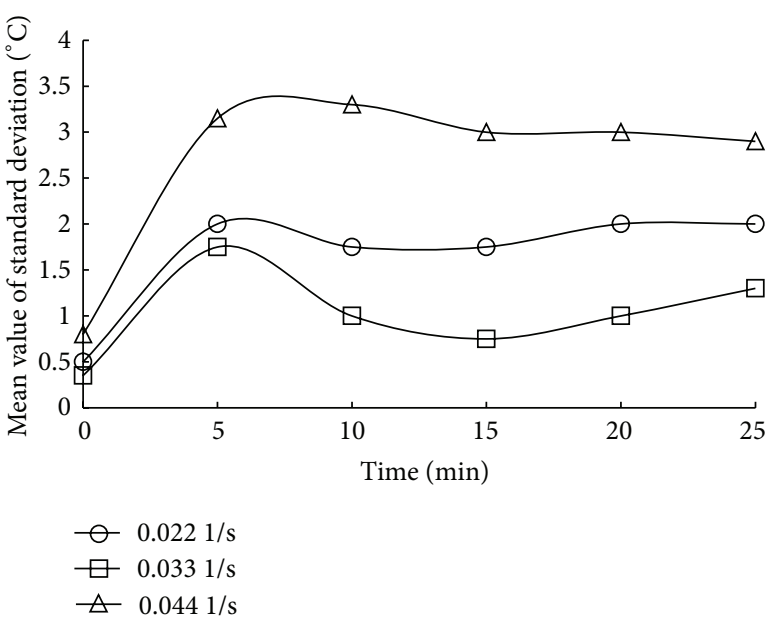

Figure 7: Effect of volumetric displacement on the temperature evenness of Brassica chinensis surface during vacuum cooling.

water was too limited to be transported to the margin from petiole. At the end of the vacuum cooling process, the final temperature of each point at leaf part rose with the increase in distance from the main vein. To obtain a uniform temperature distribution of the leaf during vacuum cooling, using an optimal volumetric displacement is worth trying. Furthermore, to obtain a better result, we suggest a humidified screen can be embedded into the current equipment used in this paper to weaken the IR effect of wall temperature on the product. Furthermore, more final pressures should be tried other than $600 \mathrm{~Pa}$, because there is always diversity among different samples grown in different environments and in different seasons.

\section{Conflict of Interests}

The authors declare that there is no conflict of interests regarding the publication of this paper.

\section{Acknowledgment}

This work was supported by China Postdoctoral Science Foundation Funded Project (2014M561491).

\section{References}

[1] R. B. Waghmare and U. S. Annapure, "Combined effect of chemical treatment and/or modified atmosphere packaging (MAP) on quality of fresh-cut papaya," Postharvest Biology and Technology, vol. 85, pp. 147-153, 2013.

[2] B. B. Mishra, S. Gautam, and A. Sharma, "Browning of freshcut eggplant: impact of cutting and storage," Postharvest Biology and Technology, vol. 67, pp. 44-51, 2012.

[3] T. Iqbal, F. A. S. Rodrigues, P. V. Mahajan, and J. P. Kerry, "Effect of Time, temperature, and slicing on respiration rate of mushrooms," Journal of Food Science, vol. 74, no. 6, pp. E298E303, 2009.

[4] C. James, G. Purnell, and S. J. James, "A critical review of dehydrofreezing of fruits and vegetables," Food and Bioprocess Technology, vol. 7, no. 5, pp. 1219-1234, 2014. 
[5] C. H. Feng, L. Drummond, Z. H. Zhang, D.-W. Sun, and Q. J. Wang, "Vacuum cooling of meat products: current state-ofthe-art research advances," Critical Reviews in Food Science and Nutrition, vol. 52, no. 11, pp. 1024-1038, 2012.

[6] K. McDonald and D.-W. Sun, "Vacuum cooling technology for the food processing industry: a review," Journal of Food Engineering, vol. 45, no. 2, pp. 55-65, 2000.

[7] C. M. Augusto, J. B. Ribeiro, A. R. Gaspar, V. R. Ferreira, and J. J. Costa, "A mathematical model describing the two stages of low-pressure-vaporization of free water," Journal of Food Engineering, vol. 112, no. 4, pp. 274-281, 2012.

[8] J. F. Cepeda, C. L. Weller, H. Thippareddi, M. Negahban, and J. Subbiah, "Modeling cooling of ready-to-eat meats by $3 \mathrm{D}$ finite element analysis: validation in meat processing facilities," Journal of Food Engineering, vol. 116, no. 2, pp. 450-461, 2013.

[9] M. Rinaldi, E. Chiavaro, and R. Massini, "Mathematical modelling of heat transfer in Mortadella bologna PGI during evaporative pre-cooling," International Journal of Food Engineering, vol. 10, no. 2, pp. 233-241, 2014.

[10] S. Y. He, G. C. Zhang, Y. Q. Yu, R. G. Li, and Q. R. Yang, "Effects of vacuum cooling on the enzymatic antioxidant system of cherry and inhibition of surface-borne pathogens," International Journal of Refrigeration, vol. 36, no. 8, pp. 2387-2394, 2013.

[11] C.-H. Feng, L. Drummond, Z.-H. Zhang, and D.-W. Sun, "Effects of processing parameters on immersion vacuum cooling time and physico-chemical properties of pork hams," Meat Science, vol. 95, no. 2, pp. 425-432, 2013.

[12] C.-H. Feng, L. Drummond, Z.-H. Zhang, and D.-W. Sun, "Evaluation of innovative immersion vacuum cooling with different pressure reduction rates and agitation for cooked sausages stuffed in natural or artificial casing," LWT-Food Science and Technology, vol. 59, no. 1, pp. 77-85, 2014.

[13] H. M. Ozturk and H. K. Ozturk, "Effect of pressure on the vacuum cooling of iceberg lettuce," International Journal of Refrigeration, vol. 32, no. 3, pp. 395-403, 2009.

[14] X.-Y. Song and B.-L. Liu, "The optimization of volumetric displacement can uniformize the temperature distribution of heated ham during a vacuum cooling process," Food Science and Technology Research, vol. 20, no. 1, pp. 43-49, 2014.

[15] C. Primo-Martín, H. de Beukelaer, R. J. Hamer, and T. van Vliet, "Fracture behaviour of bread crust: effect of bread cooling conditions," Journal of Food Engineering, vol. 89, no. 3, pp. 285290, 2008.

[16] S. Y. He, G. P. Feng, H. S. Yang, Y. Wu, and Y. F. Li, "Effects of pressure reduction rate on quality and ultrastructure of iceberg lettuce after vacuum cooling and storage," Postharvest Biology and Technology, vol. 33, no. 3, pp. 263-273, 2004.

[17] L. J. Wang and D.-W. Sun, "Numerical analysis of the threedimensional mass and heat transfer with inner moisture evaporation in porous cooked meat joints during vacuum cooling," Transactions of the American Society of Agricultural Engineers, vol. 46, no. 1, pp. 107-115, 2003.

[18] R. Zhao, E. Chen, M. Lin, D.-W. Sun, and B. Xu, "Characteristics of chamber temperature change during vacuum cooling," Journal of Food Process Engineering, vol. 32, no. 2, pp. 177-186, 2009.

[19] L. Drummond and D.-W. Sun, "Evaluation of the immersion vacuum cooling of cooked beef joints-mathematical simulation of variations in beef size and porosity and pressure reduction rates," Innovative Food Science \& Emerging Technologies, vol. 16, pp. 205-210, 2012.
[20] K. Iwabuchi and K. Kurata, "Short-term and long-term effects of low total pressure on gas exchange rates of spinach," Advances in Space Research, vol. 31, no. 1, pp. 241-244, 2003.

[21] C.-H. Feng and D.-W. Sun, "Optimisation of immersion vacuum cooling operation and quality of Irish cooked sausages by using response surface methodology," International Journal of Food Science and Technology, vol. 49, no. 8, pp. 1850-1858, 2014. 

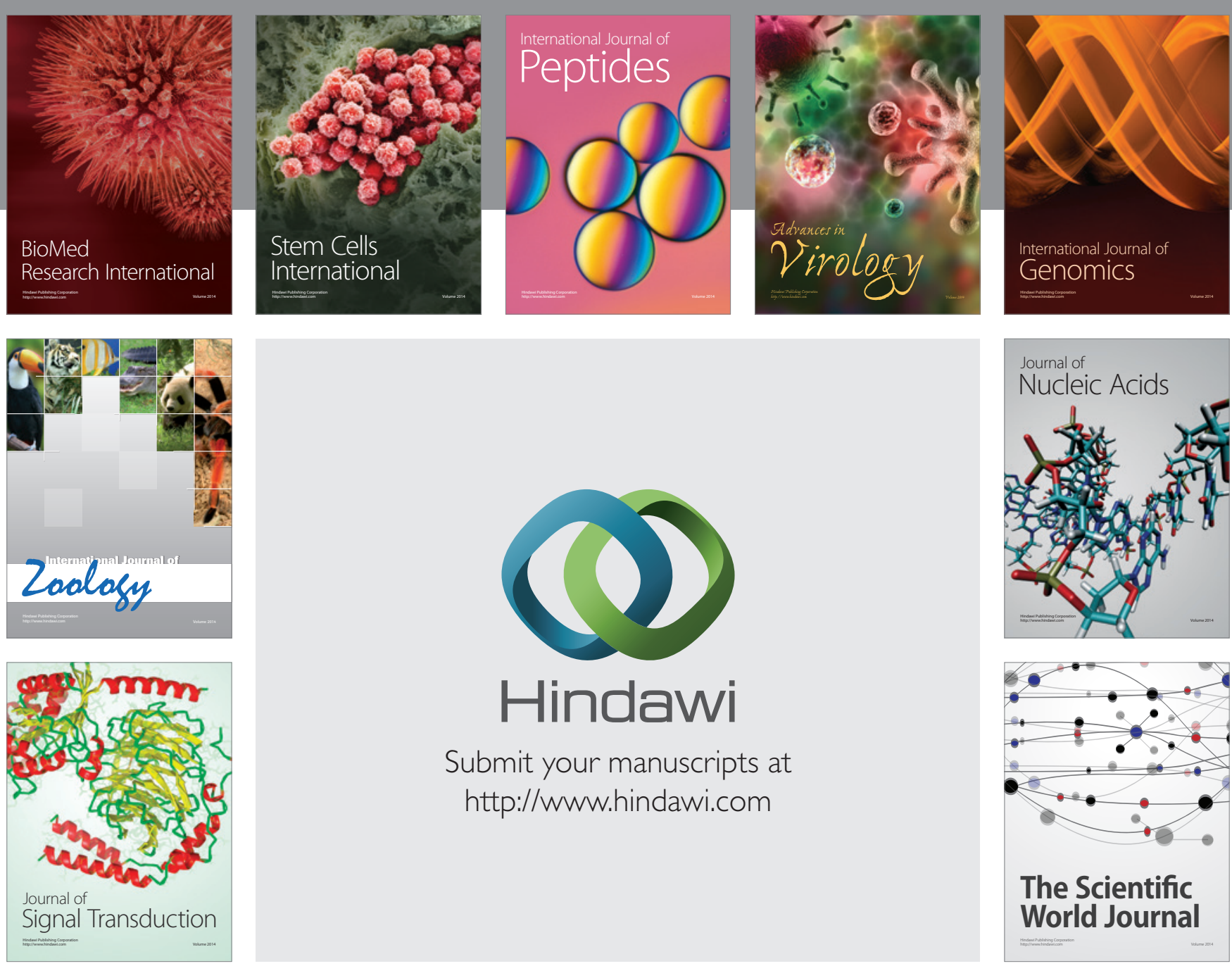

Submit your manuscripts at

http://www.hindawi.com
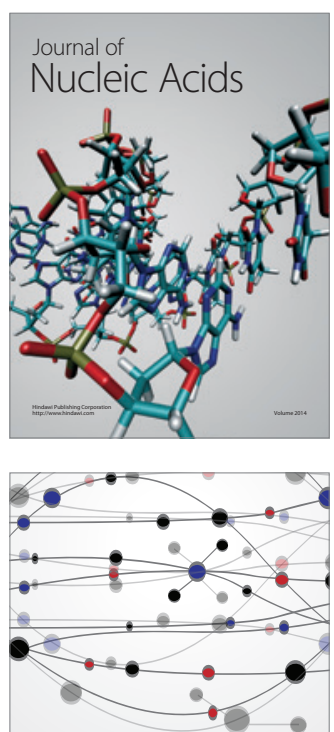

The Scientific World Journal
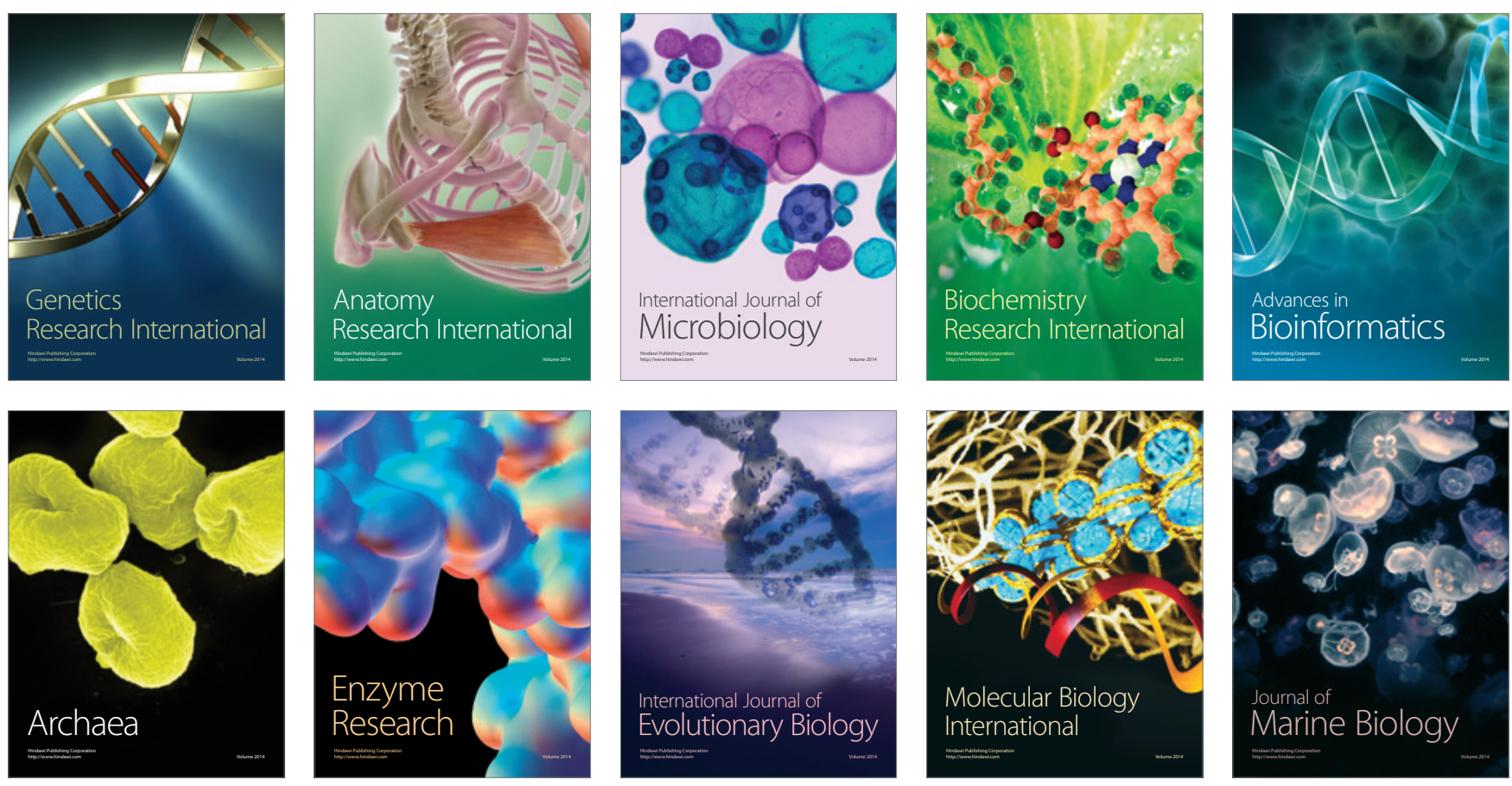